\title{
Employment of patients with kidney failure treated with dialysis or kidney transplantation-a systematic review and meta- analysis
}

\author{
Lilli Kirkeskov ${ }^{1 *}$, Rasmus K. Carlsen², Thomas Lund ${ }^{1,3}$ and Niels Henrik Buus ${ }^{4}$
}

\begin{abstract}
Background: Patients with kidney failure treated with dialysis or kidney transplantation experience difficulties maintaining employment due to the condition itself and the treatment. We aimed to establish the rate of employment before and after initiation of dialysis and kidney transplantation and to identify predictors of employment during dialysis and posttransplant.
\end{abstract}

Methods: This systematic review and meta-analysis were carried out according to the Preferred Reporting Items for Systematic Reviews and Meta-Analysis (PRISMA) guidelines for studies that included employment rate in adults receiving dialysis or a kidney transplant. The literature search included cross-sectional or cohort studies published in English between January 1966 and August 2020 in the PubMed, Embase, and Cochrane Library databases. Data on employment rate, study population, age, gender, educational level, dialysis duration, kidney donor, ethnicity, dialysis modality, waiting time for transplantation, diabetes, and depression were extracted.

Quality assessment was performed using the Newcastle-Ottawa Scale. Meta-analysis for predictors for employment, with odds ratios and confidence intervals, and tests for heterogeneity, using chi-square and $I^{2}$ statistics, were calculated. PROSPERO registration number: CRD42020188853.

Results: Thirty-three studies included 162,059 participants receiving dialysis, and 31 studies included 137,742 participants who received kidney transplantation. Dialysis patients were on average 52.6 years old (range: 16-79; 60.3\% male), and kidney transplant patients were 46.7 years old (range: 18-78; 59.8\% male). The employment rate (weighted mean) for dialysis patients was $26.3 \%$ (range: $10.5-59.7 \%$ ); the employment rate was $36.9 \%$ pretransplant (range: 25-86\%) and 38.2\% posttransplant (range: 14.2-85\%). Predictors for employment during dialysis and posttransplant were male, gender, age, being without diabetes, peritoneal dialysis, and higher educational level, and predictors of posttransplant: pretransplant employment included transplantation with a living donor kidney, and being without depression.

Conclusions: Patients with kidney failure had a low employment rate during dialysis and pre- and posttransplant. Kidney failure patients should be supported through a combination of clinical and social measures to ensure that they remain working.

\footnotetext{
*Correspondence: Lilli.Kirkeskov@regionh.dk

${ }^{1}$ Centre of Social Medicine, University Hospital Bispebjerg-Frederiksberg,

Nordre Fasanvej 57, Vej 8, Opgang 2.2., 2000 Frederiksberg, Denmark

Full list of author information is available at the end of the article
}

(C) The Author(s) 2021. Open Access This article is licensed under a Creative Commons Attribution 4.0 International License, which permits use, sharing, adaptation, distribution and reproduction in any medium or format, as long as you give appropriate credit to the original author(s) and the source, provide a link to the Creative Commons licence, and indicate if changes were made. The images or other third party material in this article are included in the article's Creative Commons licence, unless indicated otherwise in a credit line to the material. If material is not included in the article's Creative Commons licence and your intended use is not permitted by statutory regulation or exceeds the permitted use, you will need to obtain permission directly from the copyright holder. To view a copy of this licence, visit http://creativecommons.org/licenses/by/4.0/. The Creative Commons Public Domain Dedication waiver (http://creativeco mmons.org/publicdomain/zero/1.0/) applies to the data made available in this article, unless otherwise stated in a credit line to the data. 
Keywords: Kidney failure, Renal failure, End-stage renal disease, ESRD, Haemodialysis, Peritoneal dialysis, Kidney transplantation, Renal transplantation, Employment rate

\section{Background}

Kidney failure with a need for renal replacement therapy affects approximately $0.1 \%$ of the global population. According to National Kidney Foundation statistics, more than 2 million people worldwide receive chronic dialysis treatment or are living with a functioning kidney transplant $[1,2]$. Kidney failure reduces quality of life, increases psychosocial problems and has profound implications for the maintenance of normal employment $[3,4]$. To a large extent, this is a consequence of disease-related comorbidity and uraemia-related symptoms, but it is also due to time-consuming treatments with haemodialysis or peritoneal dialysis. Therefore, kidney failure entails not only high costs because of the treatment itself but also results in lost productivity due to a reduced labour force. A Canadian study stated that kidney diseases cost more than 217 billion Canadian dollars annually in health care services alone [5]. In addition to this comes loss of labour force.

Over the past decades, replacement therapy in kidney failure has improved in terms of home-based dialysis modalities with automated peritoneal dialysis or home haemodialysis, rendering it easier for some patients to plan their time. Additionally, an increasing number of patients are receiving kidney transplants, and the survival rate following transplantation has increased [6]. Despite this, studies from all over the world have shown that many patients with kidney failure are not employed [7].

The employment rate in the general population of 15 to 64 years of age ranges between countries from 46 to $47 \%$ in South Africa and India to $85 \%$ in Iceland. The average employment rate in the Organization for Economic Cooperation and Development (OECD) countries is 69\% [8]. The employment rate is lower in subjects below the upper secondary educational level than in those at or above the upper secondary level [8]. For subjects suffering from chronic diseases, the employment rate is lower. Prognostic factors for employment include severity of the chronic disease, employment status before getting the condition and educational level [9-11]. These somatic and social factors may also influence employment status in kidney failure patients.

Previous studies have reported employment rates and predictors for employment during dialysis or after kidney transplantation, but the results have never been summarized in a systematic review of kidney failure patients receiving dialysis or having a kidney transplantation [12-14]. The first aim of this study was to conduct a systematic review focusing on the employment rate before and after the initiation of dialysis (haemodialysis and peritoneal dialysis) and after kidney transplantation. The second aim was to establish predictors of employment during dialysis and posttransplant. The predefined predictors were socioeconomic factors, such as age, gender, level of education, and pretransplant employment, disease-related factors, such as dialysis modality, time on dialysis, waiting time for transplant, and donor type, and comorbidities, such as diabetes and depression.

\section{Methods \\ Protocol}

This systematic review was carried out according to Preferred Reporting Items for Systematic Reviews and Meta-Analysis (PRISMA) [15] for studies that included employment rate in kidney failure patients during dialysis and after kidney transplantation. The PROSPERO registration number is CRD42020188853.

\section{Selection criteria and search strategies}

The literature search included the period from January 1966 to August 2020 in the PubMed, Embase, and Cochrane Library databases using the following search terms: ((chronic* kidney disease OR chronic* renal disease OR kidney transplant* OR renal transplant* OR dialysis OR hemodialysis OR peritoneal dialysis) AND (employment OR work ability OR disability pension)). Articles in English were included. The search was performed in the following order: PubMed, Embase, and Cochrane Library. Articles were selected primarily based on the titles and abstracts if necessary. Studies from around the world were included. Articles including employment, work ability or disability, return to work or disability pension were selected, and duplicates were excluded. Reference lists in the selected articles were reviewed, and more articles were included if relevant. Full-time and part-time employment, but not 'working as housewives', was included in our definition of employment.

\section{Data extraction, quality assessment and risk of bias}

The data collected included author names, year of publication, study design, data collection dates, employment rate, study population, age, gender, educational level, dialysis duration, kidney donor, ethnicity, dialysis modality, waiting time for transplantation, diabetes, and depression. Quality assessment was independently 
assessed by two reviewers (LK and RKC) using the Newcastle-Ottawa Scale (NOS) for cross-sectional and cohort studies [16] to assess the risk of bias for all studies. Any disagreements were resolved by discussion until consensus was reached. The rating scale was based on 9 items that divided the studies into high (7-9), moderate (4-6) or low (1-3) quality. A low NOS score (range 1-3) indicated a high risk of bias, and a high NOS score (range 7-9) indicated a lower risk of bias. For cross-sectional studies, the quality assessment included representativeness of the sample, sample size, nonrespondents, ascertainment of the risk factor, comparability, assessment of outcome, and statistical testing. For cohort studies, the assessment included representativeness of the exposed cohort, selection of the nonexposed cohort, ascertainment of exposure, demonstration that the outcome of interest was not present at the start of study, comparability, assessment of outcome, length of follow-up and adequacy of follow-up.

\section{Analytical approach}

For outcomes reported in numbers or percentages, odds ratios and 95\% confidence intervals (CIs) were calculated if possible. Meta-analysis for the predefined predictors for employment before and during dialysis and after kidney transplantation, including age, gender, level of education, previous employment, dialysis modality, time on dialysis, waiting time for transplant, donor type and comorbidities such as diabetes and depression, were carried out. In addition to the predefined predictors, attempts were made to find information on ethnicity, health insurance, self-assessed ability to work and quality of life, but there were only enough data on ethnicity for analysis. Tests for heterogeneity was performed using chi-square and $\mathrm{I}^{2}$ statistics, where an $\mathrm{I}^{2}$ value below $40 \%$ might not be important, $30-60 \%$ might represent moderate heterogeneity, $50-90 \%$ represents substantial heterogeneity, and $75-100 \%$ indicates considerable heterogeneity.

Meta-analysis for predictors for employment, with odds ratios and confidence intervals, and tests for heterogeneity were calculated using Review Manager software (RevMan, version 5.3. Copenhagen: The Nordic Cochrane Centre, The Cochrane Collaboration, 2014).

\section{Results}

\section{General description of included studies}

The search yielded 2310 references addressing kidney failure and employment. From the titles, 133 studies were considered relevant for evaluation, and of those, 58 met the inclusion criteria. Figure 1 shows the results of the systematic search strategy.
Table 1 summarizes the general characteristics of the studies. In total, 27 studies described employment in kidney failure patients during dialysis [17-43], 25 addressed employment after kidney transplantation $[3,4,12,13$, 44-64], and 6 [14, 65-69] addressed both dialysis and kidney transplantation. In total, 33 studies regarding dialysis and 31 regarding kidney transplantation were included, with a total of 162,059 and 137,742 participants, respectively. The publication year of the included studies ranged from 1981 to 2020 (median: 2013). Most of the studies $(81 \%)$ were cross-sectional in design, analysing data at a specific point in time. The cross-sectional studies [3, 12-14, 17-19, 21, 22, 24-39, 41-49, 51, 54, $55,57,59,61-64,66-69]$ were small to medium sized with a median of 139-233 participants for kidney transplant and dialysis patients, while the cohort studies [4, $20,23,40,50,52,53,56,58,60,65]$ were mainly larger population studies (median of 2103 for dialysis patients and 1254 for kidney transplant patients). More than half of the studies were single-centre studies, and the studies were mainly from high-income countries. Study details are shown in Tables 1, 2 and 3.

\section{General description of study participants}

The dialysis patients were on average 52.6 (16-79) years old, and the kidney transplant patients were 46.7 (18-78) years old. More than half of the dialysis and kidney transplant patients were males, 60.3 and $59.8 \%$, respectively.

\section{Employment rate during dialysis and pre- and posttransplant Before and during dialysis}

The weighted mean for the employment rate during dialysis was 26.3\% (range: 10.5-59.7), as shown in Tables 4 and 5 . The employment rate was $21.6 \%$ in the 16 studies, which excluded patients more than 65 years of age [14, $20,22,23,25,26,29,30,33,35,39-42,65,66,69]$. The U.S. generally appeared to have a lower employment rate among patients receiving dialysis treatment. Removing the studies conducted in the U.S. resulted in a weighted mean of $44.4 \%$ compared to $24.8 \%$ in the U.S. A total of 23 cross-sectional studies found an employment rate of $24.9 \%$, compared to an employment rate of $51.7 \%$ in the 3 cohort studies.

In general, the employment rate decreased after the initiation of dialysis. In 9 studies, data before and after the initiation of dialysis were available $[20,24,27,31$, $39,40,65,67,68]$. In these studies, the employment rate decreased by $16.4 \%$ (weighted mean), ranging from a decrease of 5.2 to $58.5 \%$ within and between countries.

In a study from the U.S. of 1643 dialysis patients, 36\% were employed before dialysis and $11.6 \%$ after the start of dialysis [27]. In a Japanese study, $63 \%$ were employed 


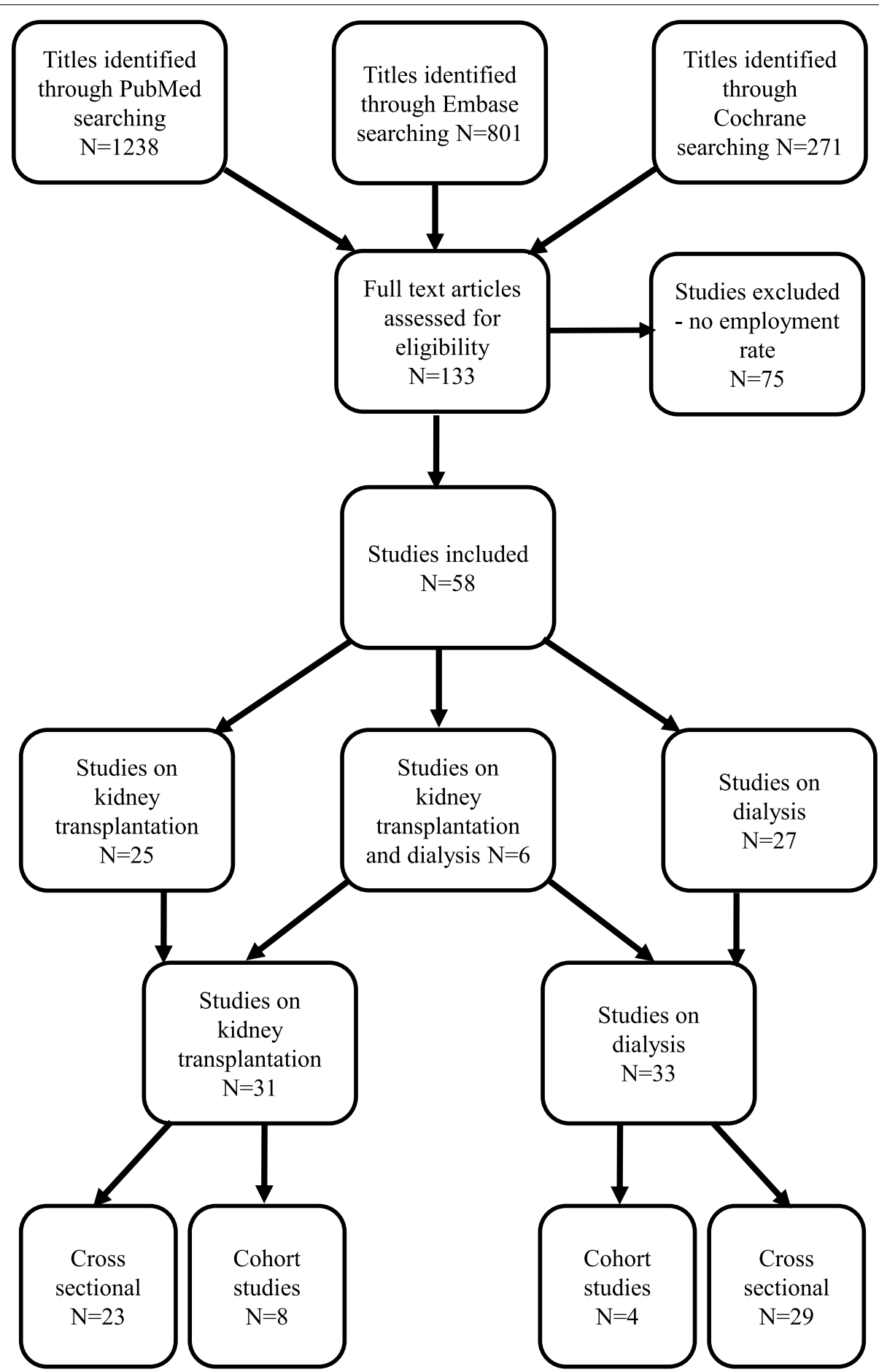

Fig. 1 Flow chart illustrating the systematic search for studies examining employment outcomes in patients with kidney failure receiving dialysis or transplantation

before dialysis and $49 \%$ after the start of dialysis; $50.7 \%$ of haemodialysis (HD) patients and $48 \%$ of peritoneal dialysis (PD) patients were employed [31].
Patients receiving PD had a higher employment rate, $58.8 \%[14,20,28,29,31,32,34,39,41,42,66,67]$, than patients on HD, 39.5\% [14, 17-20, 22, 23, 29-34, 37, 39, $41,42,66-69]$. 
Table 1 General characteristics of the included studies, by dialysis and kidney transplantion

\begin{tabular}{|c|c|c|}
\hline Geography & Dialysis $(n=33)$ & $\begin{array}{l}\text { Kidney } \\
\text { transplantion } \\
(n=31)\end{array}$ \\
\hline Europe & 10 & 13 \\
\hline North America & 11 & 14 \\
\hline $\begin{array}{l}\text { Others (Asia, South America, New } \\
\text { Zealand) }\end{array}$ & 12 & 4 \\
\hline \multicolumn{3}{|l|}{ Study design } \\
\hline Cross sectional & 29 & 23 \\
\hline Cohort study & 4 & 8 \\
\hline \multicolumn{3}{|l|}{ Study sampling method } \\
\hline Single-centre & 13 & 24 \\
\hline Multicentre & 13 & 2 \\
\hline Registry & 7 & 5 \\
\hline \multicolumn{3}{|l|}{ Type of dialysis $^{a}$} \\
\hline Haemodialysis & 15 & \\
\hline Peritoneal dialysis & 10 & \\
\hline Dialysis-modality unknown & 17 & \\
\hline \multicolumn{3}{|l|}{ Number of participants } \\
\hline \multicolumn{3}{|l|}{ Cross sectional studies } \\
\hline Median & 233 & 139 \\
\hline Range & $43-105,636$ & $34-1278$ \\
\hline SD & 22,449 & 255 \\
\hline \multicolumn{3}{|l|}{ Cohort studies } \\
\hline Median & 2103 & 1253 \\
\hline Range & $359-4734$ & $358-71,976$ \\
\hline SD & 1997 & 27,826 \\
\hline
\end{tabular}

a Does not sum up to 33 because some studies included more than one type of dialysis

\section{Pre- and posttransplant}

The pretransplant employment rate was $36.9 \%$ (weighted mean), ranging from 25 to $86 \%$ between continents. The posttransplant employment rate was $38.2 \%$ (weighted mean, all studies), ranging between 14.2 and $85 \%$ within and between continents, as shown in Tables 4 and 5 . The employment rate was $34.4 \%$ when including only the 18 studies of kidney transplant patients that excluded patients 65 years or more (i.e., those not of working age) $[3,4,12-14,46,48,49,52-55,58,60,61,63,65,66]$. In the 20 cross-sectional studies, the employment rate was $45 \%$ (weighted mean) compared to $37.1 \%$ (weighted mean) in 8 cohort studies (not significant).

In 14 studies, both pre- and posttransplant data were available $[4,13,44,46,47,50,55,57,60,62,65,67,68]$. In these studies, the change in the employment rate from pre- to posttransplant ranged from a decrease of $30 \%$ to an increase of $3.5 \%$. The majority of the studies assessed the employment rate 1 year posttransplant. Only one study examined employment rates 1 and 5 years posttransplant, which were 38.1 and $35.6 \%$, respectively (full-time work) [56].

A Swiss study including 354 patients identified 32.9\% of patients working full-time 1 year before transplantation, $20.9 \%$ working part-time and $11.9 \%$ working parttime with partial disability pension; in total, $65.7 \%$ were employed. One year posttransplant, $36.2 \%$ worked fulltime, $19.5 \%$ worked part-time, and $10.6 \%$ worked parttime with partial disability pension, for a total of $66.3 \%$ being employed [13]. Another Swiss study found approximately the same relatively high rate of employment preand posttransplant [4]. In a cohort study performed in the U.S. among 105,181 post-kidney transplant patients, $34.2 \%$ worked full-time, and $6 \%$ worked part-time pretransplant. One year posttransplant, $38.1 \%$ worked fulltime, and $4.3 \%$ worked part-time [56]. In another U.S. study from 2014, among 27,981 kidney failure patients of working age (18-64 years), 33\% worked pretransplant, and $32.1 \%$ worked 1 year posttransplant [60].

\section{Dialysis versus posttransplant employment}

The employment rate was $26.4 \%$ during dialysis (weighted mean) and $37.4 \%$ posttransplant $(p<0.0001)$. The difference remained significant when excluding data from U.S. but the employment rates were higher (44.4\% vs. $53.6 \%$ ). The posttransplant patients were on average slightly younger than the dialysis patients. The employment rate was $21.6 \%$ vs. $34.4 \%$ for dialysis and posttransplant patients, respectively, when we excluded patients 65 years or older (i.e., those not of working age). This supports a real difference between the groups.

\section{Predictors for employment during dialysis and posttransplant}

\section{During dialysis}

Twelve studies had information on normative comparison data to use for meta-analysis of predictors for employment during dialysis, but for only a few of the predictors: dialysis modality (PD vs. HD), diabetes vs. nondiabetes, educational level (more than high school vs. high school or less), gender (male vs. female) and age $[4,20,22,23,27,33,34,39,40,42,55,58]$. Predictors for employment during dialysis were not having diabetes, educational level greater than high school, peritoneal dialysis, and male gender. Heterogeneity was low among studies with nondiabetic patients, moderate among studies examining educational level and substantial/high among studies examining peritoneal dialysis and gender, as indicated by the $\mathrm{I}^{2}$ values (Table 6 and Figure 2a-e; Supplementary material). In three studies, age was available for analysis. Young age was also a predictor for employment, with a mean difference of -2.68 

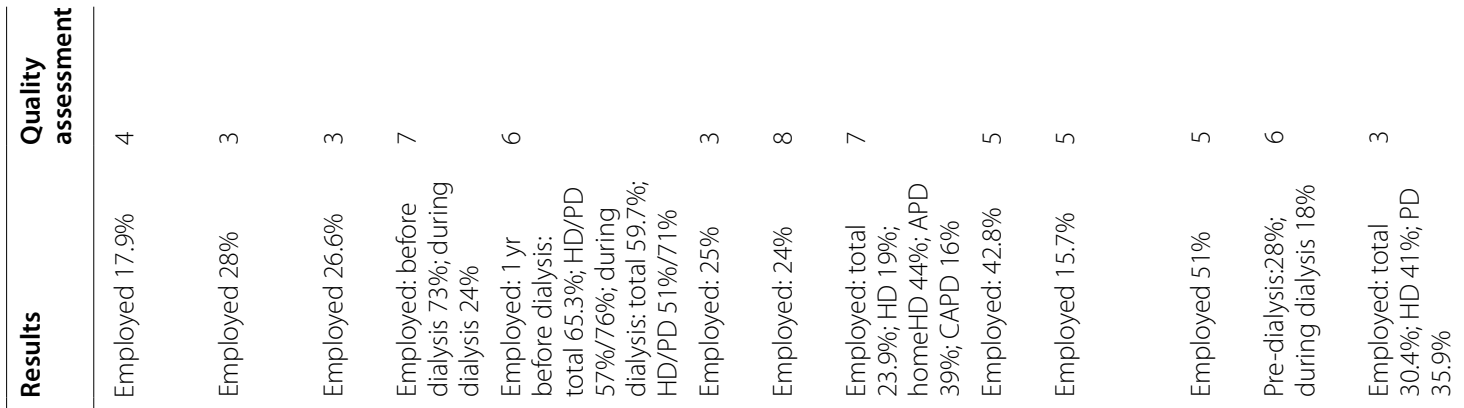

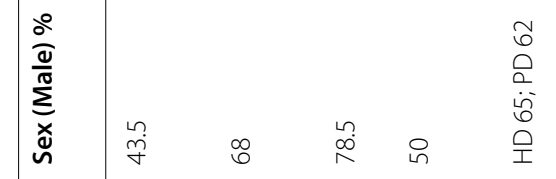

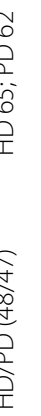

8 น

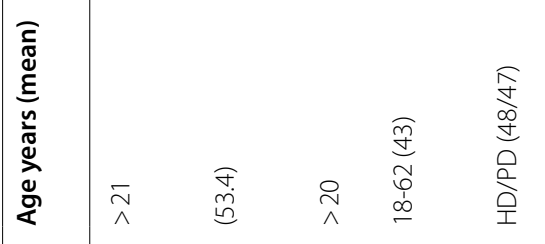

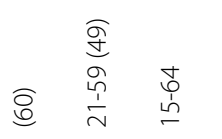

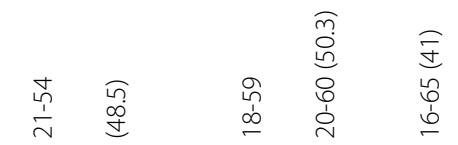

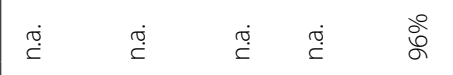

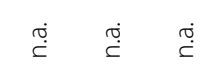

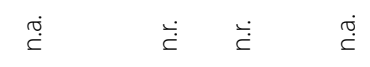

.

$\frac{2}{20}$

๑.

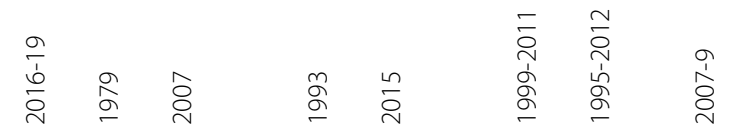

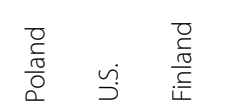

บ่:

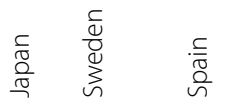

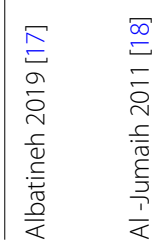

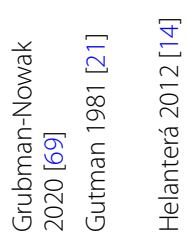

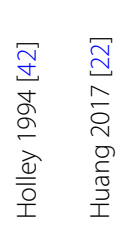

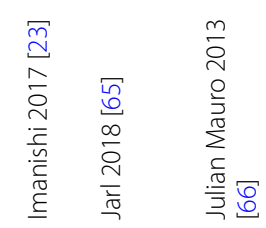




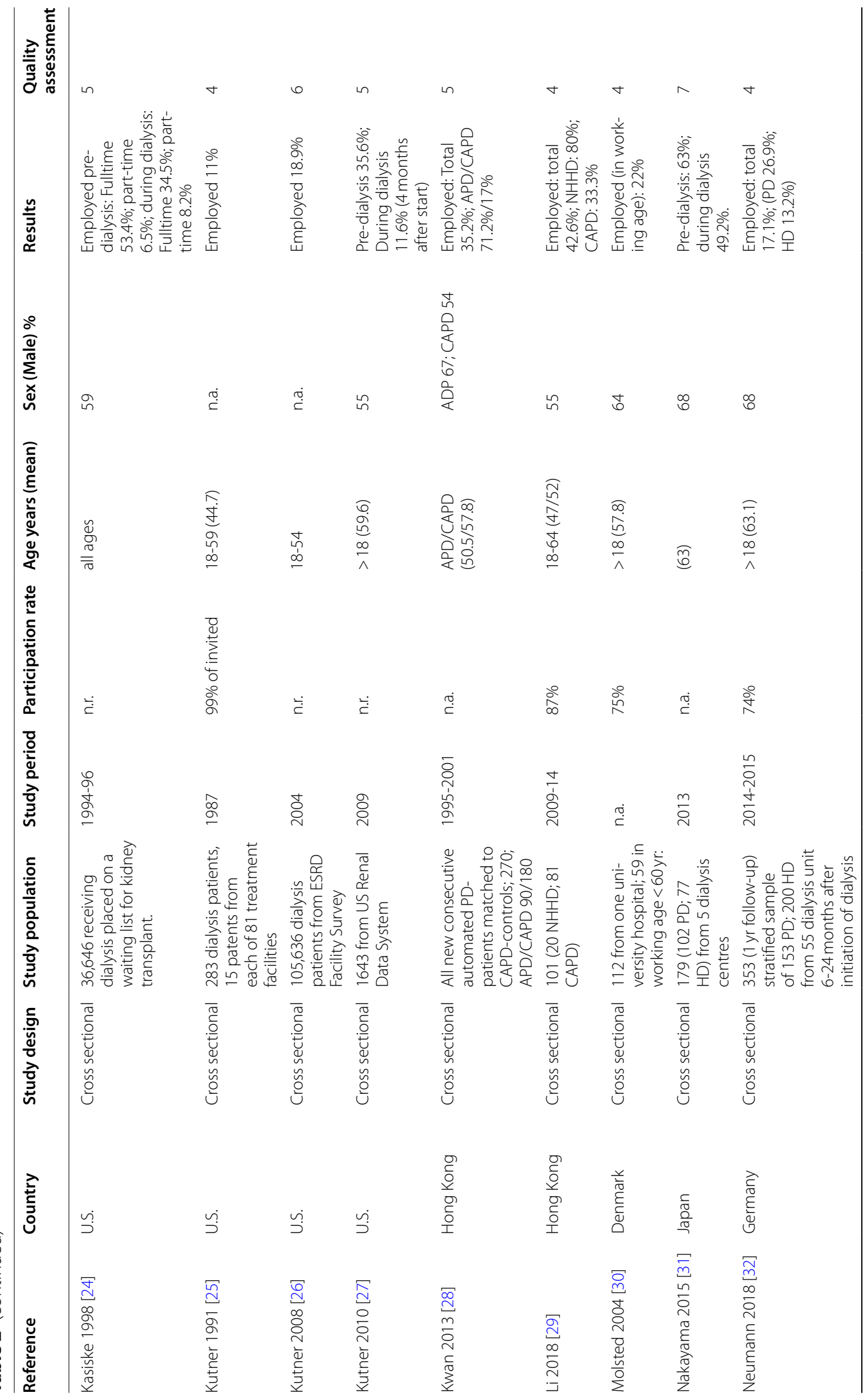




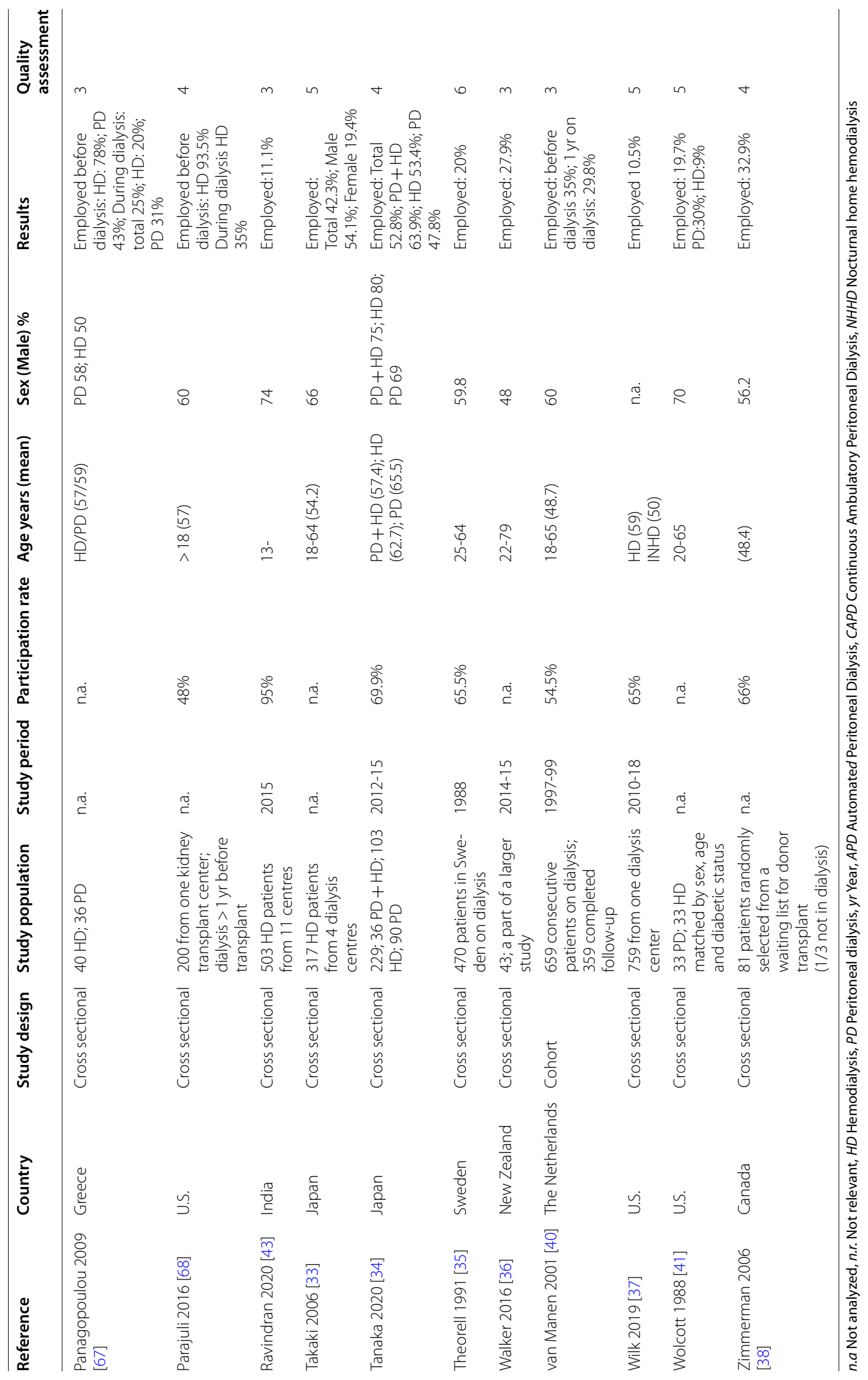




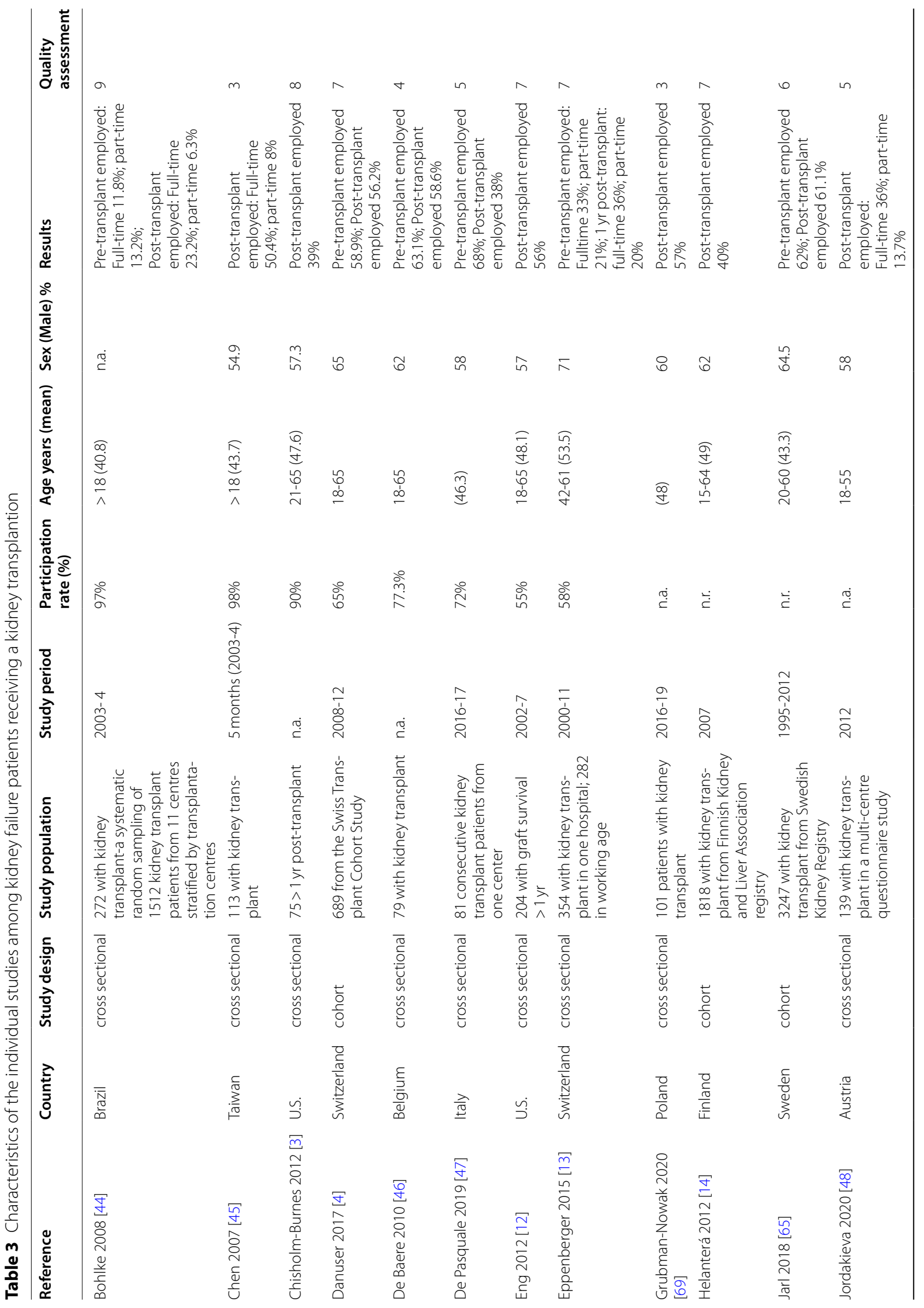


Kirkeskov et al. BMC Nephrol $\quad$ (2021) 22:348

Page 10 of 17

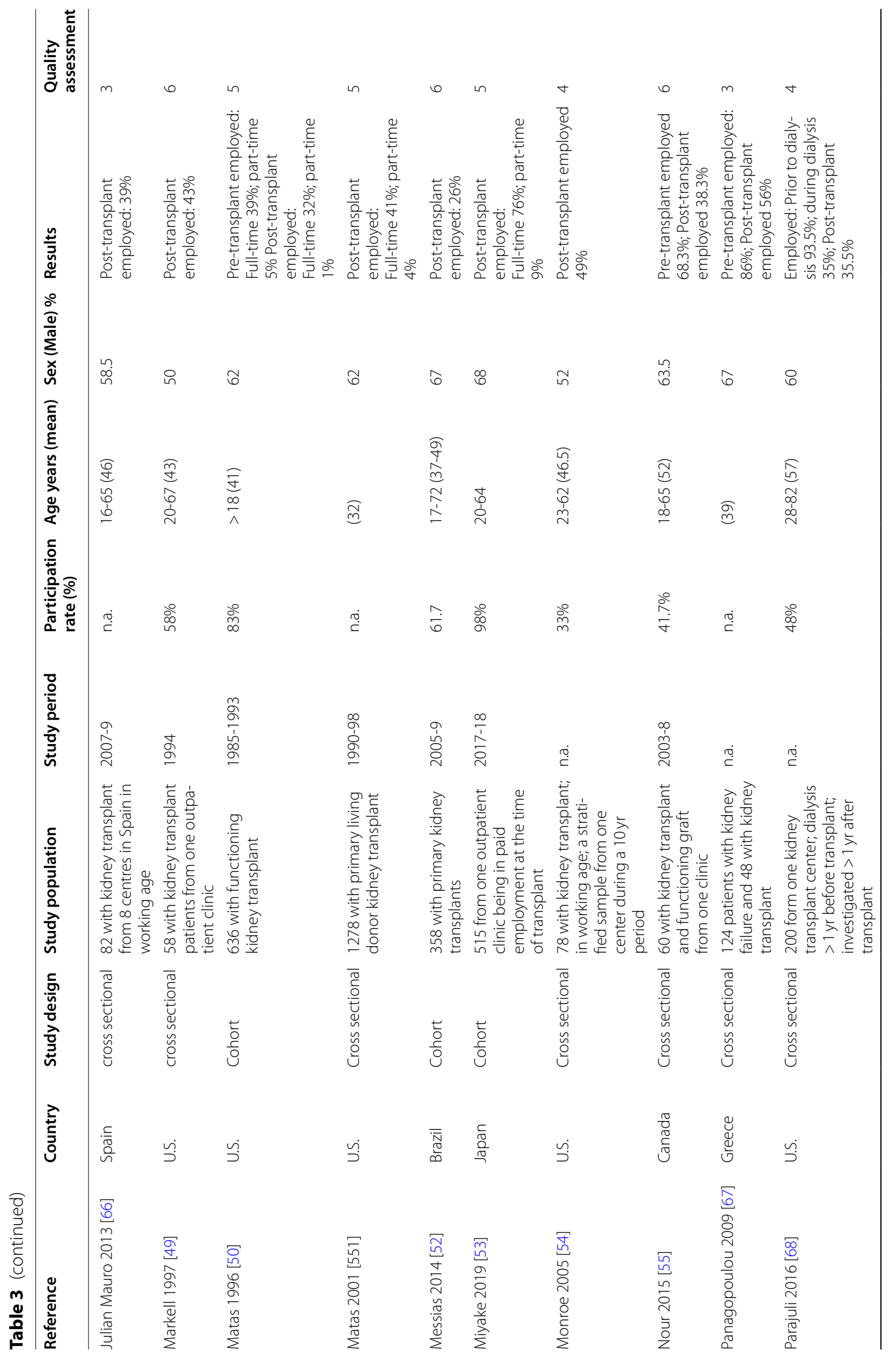




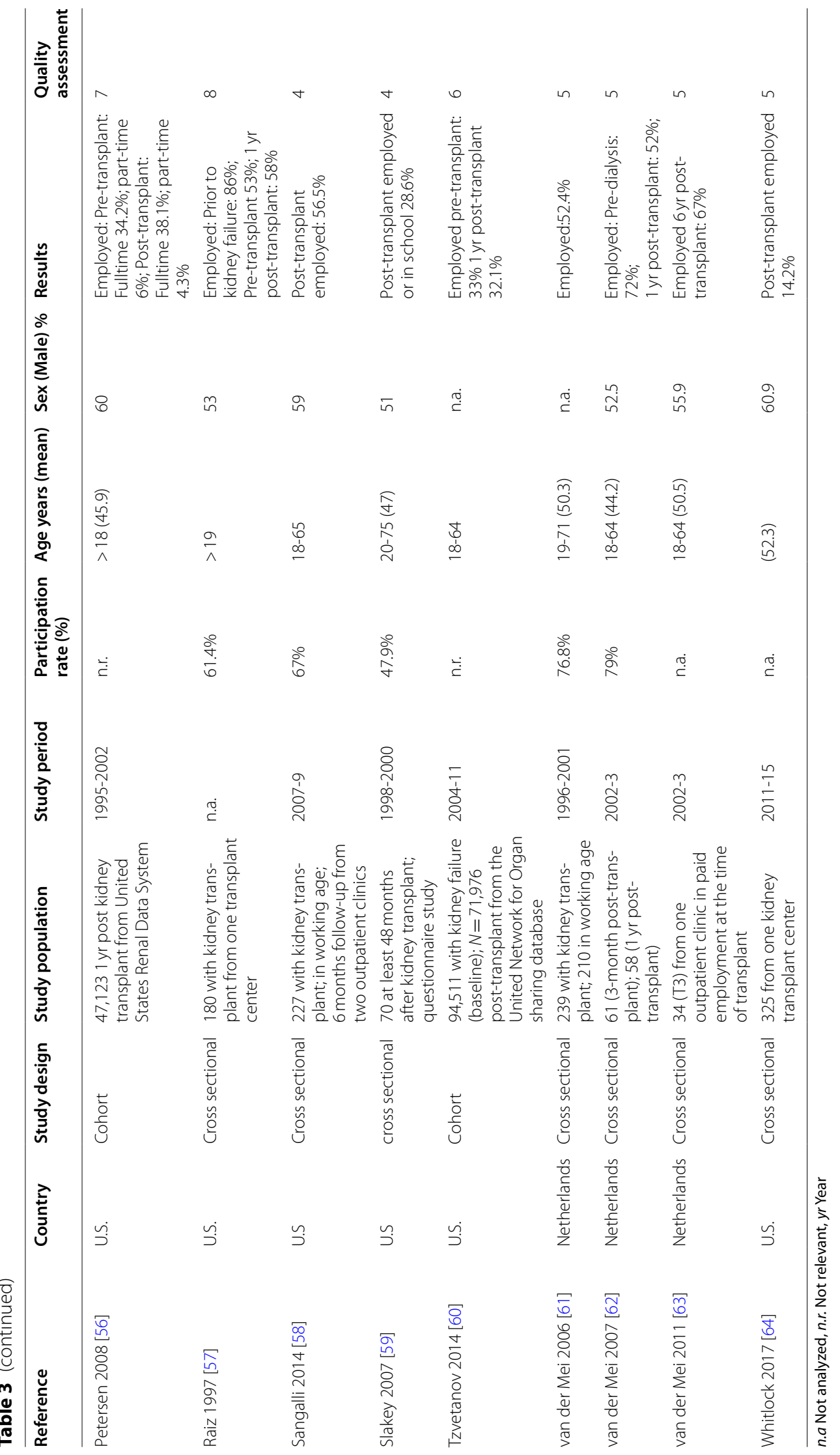


Table 4 Employment rate in patients pre-dialysis and during dialysis, by continent (Weighted Mean, Standard deviation, SD, and Range)

\begin{tabular}{|c|c|c|c|c|c|c|}
\hline \multirow[t]{2}{*}{ Continent } & \multicolumn{3}{|l|}{ Pre-dialysis } & \multicolumn{3}{|l|}{ During Dialysis } \\
\hline & Weighted mean (\%) & SD & range & Weighted mean (\%) & SD & range \\
\hline Europe & 57.1 & 16.7 & $28.0-65.3$ & 45.8 & 12.3 & $17.1-59.7$ \\
\hline North America & 59.1 & 21.9 & $35.6-93.5$ & 24.8 & 12.0 & $10.5-42.9$ \\
\hline $\begin{array}{l}\text { Other (Asia, South America, } \\
\text { New Zealand) }\end{array}$ & 63.0 & & & 41.4 & 14.3 & $11.1-52.8$ \\
\hline Total & 59.0 & 22.0 & $28.0-93.5$ & 26.3 & 13.5 & $10.5-59.7$ \\
\hline
\end{tabular}

Table 5 Employment rate in patients pre- and post-kidney transplantation, by continent (Weighted Mean, SD, Range)

\begin{tabular}{|c|c|c|c|c|c|c|}
\hline \multirow[t]{2}{*}{ Continent } & \multicolumn{3}{|l|}{ Pre-transplant } & \multicolumn{3}{|l|}{ Post-transplant } \\
\hline & Weighted mean (\%) & SD & range & Weighted mean (\%) & SD & range \\
\hline Europe & 61.3 & 11.1 & $54.0-86.0$ & 53.7 & 8.9 & $38.0-67.0$ \\
\hline North America & 36.0 & 21.2 & $33.0-85.6$ & 36.3 & 9.7 & $14.2-58.0$ \\
\hline Other (Asia) & 25.0 & & & 53.8 & 27.6 & $26.0-85.0$ \\
\hline Total & 36.9 & 19.3 & $25.0-86.0$ & 38.2 & 14.6 & $14.2-85.0$ \\
\hline
\end{tabular}

Table 6 Predictors for employment during dialysis and post-transplant

\begin{tabular}{|c|c|c|c|c|c|c|c|}
\hline & \multirow[t]{2}{*}{ No of Studies } & \multirow[t]{2}{*}{ Participants } & \multicolumn{3}{|c|}{ Heterogeneity } & \multicolumn{2}{|c|}{ Meta-analysis } \\
\hline & & & $\overline{\mathrm{Chi}^{2}}$ & $p$ & $I^{2}(\%)$ & $\overline{O R}$ & $(95 \% \mathrm{Cl})$ \\
\hline \multicolumn{8}{|l|}{ Dialysis } \\
\hline Diabetes (non-diabetic/diabetic) & 7 & 479 & 6.34 & 0.39 & $5 \%$ & 1.68 & $(1.46,1.93)$ \\
\hline Education (>high school/<=high school) & 6 & 1704 & 10.0 & 0.08 & $50 \%$ & 2.57 & $(2.06,3.21)$ \\
\hline Dialysis modality (PD/HD) & 6 & 6081 & 19.3 & 0.002 & $74 \%$ & 2.24 & $(2.01,2.51)$ \\
\hline Gender (male/female) & 6 & 215 & 128 & $<0.001$ & $96 \%$ & 4.09 & $(3.59,4.67)$ \\
\hline \multicolumn{8}{|l|}{ Post transplant } \\
\hline Gender (male/female) & 12 & 253 & 13.1 & 0.29 & $16 \%$ & 1.41 & $(1.19,1.67)$ \\
\hline Education (>high school/<=high school) & 10 & 2139 & 11.9 & 0.22 & $24 \%$ & 2.25 & $(1.85,2.75)$ \\
\hline Kidney donor (living donor /deceased donor) & 10 & 2597 & 8.7 & 0.47 & $0 \%$ & 2.74 & $(2.30,3.27)$ \\
\hline Pretransplant employed (employed/unemployed) & 8 & 74,408 & 26.8 & $<0.001$ & $74 \%$ & 13.63 & $(13.1,14.2)$ \\
\hline Diabetes (non-diabetic/diabetic) & 8 & 3114 & 15.2 & 0.03 & $54 \%$ & 1.62 & $(1.36,1.92)$ \\
\hline Ethnicity (white/other than white) & 5 & 944 & 5.1 & 0.28 & $21 \%$ & 1.95 & $(1.44,2.64)$ \\
\hline Age $(<50 \mathrm{yr} />=50 \mathrm{yr})$ & 5 & 1566 & 6.5 & 0.17 & $38 \%$ & 2.29 & $(1.85,2.84)$ \\
\hline Dialysis modality (PD/HD) & 4 & 749 & 2.7 & 0.45 & $0 \%$ & 1.55 & $(1.02,2.35)$ \\
\hline Waiting time $(<2 \mathrm{yr} />=2 \mathrm{yr})$ & 4 & 1226 & 0.2 & 0.98 & $0 \%$ & 1.82 & $(1.37,2.42)$ \\
\hline Depression (no depression/depression) & 3 & 1084 & 2.2 & 0.33 & $9 \%$ & 2.24 & $(1.53,3.27)$ \\
\hline Dialysis duration $(<2 \mathrm{yr} />=2 \mathrm{yr})$ & 2 & 477 & 3.2 & 0.08 & $68 \%$ & 3.82 & $(2.51,5.83)$ \\
\hline
\end{tabular}

(-3.2-2.15) and $\mathrm{I}^{2}$ of $77 \%$. Excluding low-quality studies from the meta-analysis did not significantly change the results but slightly increased the estimates.

\section{Posttransplant}

Fifteen of the studies reporting posttransplant employment rate also had information of normative comparison data to use for a meta-analysis of predictors for employment posttransplant $[3,4,12,13,44,48-52,55,58-60$, $63,69]$. There were enough normative data for only some 
of the predictors: pretransplant employment, educational level, donor type, dialysis modality, diabetes, waiting time for transplant, time on dialysis, depression, gender, age, and ethnicity. The predictors for posttransplant employment with low heterogeneity were having a living donor, educational level more than high school, peritoneal dialysis, male gender, younger age, being white, waiting time for transplantation, and depression and with moderate heterogeneity were pretransplant employment, being without diabetes, and shorter time in dialysis ( $<2$ years) (Table 6 and Figure 3a-k; Supplementary). Excluding low-quality studies from the meta-analysis did not significantly change the results but slightly increased the estimates.

\section{Assessment of quality of included studies}

The studies evaluating employment during dialysis were assessed as low quality $(n=8 ; 24.2 \%)[18,19,36,40$, $43,66,67,69]$, medium quality $(n=20 ; 60.6 \%)[17,20$, $22-30,32-35,37,41,42,65,68]$, or high quality $(n=4$; 12.1\%) $[14,21,31,39]$.

Based on the Newcastle-Ottawa criteria of assessment, studies of posttransplant employment were assessed as low quality (score $1-3)(n=4 ; 12.9 \%)[45,66,67,69]$, medium quality (score $4-6)(n=19 ; 61.3 \%)[46-55,58-$ $65,68]$, or high quality (score $7-9)(n=8 ; 25.8 \%)[3,4$, $12-14,44,56,57]$.

Many studies were cross-sectional single-centre studies, with a relatively small number of participants and self-reported patient data. Only 3 studies were prospective cohort studies $[4,40,50]$. When including only the high-quality studies in the analyses, the employment for dialysis patients changed from $26.3 \%$ (weighted mean, all studies) to $25.2 \%$ (weighted mean, high-quality studies) (not significant). The posttransplant employment rate changed from $36.9 \%$ (weighted mean, all studies) to $42.5 \%$ (weighted mean, high-quality studies) (not significant). The quality assessment is shown in Supplementary Tables $7 \mathrm{a}-7 \mathrm{~d}$.

\section{Discussion}

\section{Key findings}

This is the first quantitative systematic review focusing on employment rates in kidney failure patients during chronic dialysis treatment and in patients receiving kidney transplantation. In the systematic review, we found that the employment rate considerably decreased during dialysis compared to predialysis, likely because the treatment constitutes a barrier to full- or part-time employment. However, the posttransplant employment rate decreased or increased only slightly compared to rates in the pretransplant and dialysis conditions. Our analyses support that it is very difficult to remain employed during dialysis and that employment depends on a combination of personal, clinical and work-related factors.

In the meta-analysis, the strongest predictor of posttransplant employment was shown to be pretransplant employment $[4,12,13,44,49,50,52,60]$, but there was high heterogeneity among studies. Danuser et al. found that $81 \%$ of patients who worked pretransplant were still employed posttransplant [4]. Sandhu et al. showed that among a U.S. population, employment gave privileged access to and shortened the waiting time for transplantation [70]. In the two prospective cohort studies $[4,50]$, employment status before transplant was also the most important predictor for employment 12 months after kidney transplant, which supports the results of this study and the result from Sandhu et al.

Educational level was also a predictor of posttransplant employment, as patients with a higher educational level were more likely to be employed posttransplant [3, $4,12,13,44,48,55,58,59,63]$. Persons with a higher educational level may have more job opportunities and flexibility, lower physical workload, good insurance, and better health care, which may influence the possibilities for employment before kidney failure, during dialysis and posttransplant.

Being younger was also a predictor of posttransplant employment $[4,12,13,58,59]$. Danuser et al. found that younger patients were more likely to be employed before dialysis [4], which increased the chances of being in jobs during dialysis and posttransplant.

Having a living donor kidney may have also influenced employment status [3, 4, 12, 13, 44, 49, 50, 52, $55,63]$. However, the association of receiving a living donor kidney and posttransplant employment may not be causal but may depend to a greater extent on the resources of the recipient and their surroundings [71, 72]. Having diabetes and an ethnicity other than white were also associated with a lower rate of living donor kidney transplantation $[4,71,73]$ and influenced employment levels [3, 4, 12, 44, 49-52, 58], supporting this assessment. A shorter waiting time for kidney transplantation increased the possibility of posttransplant employment $[4,12,13,55]$, which was shown especially for patients receiving a living donor kidney [4]. All these factors may therefore affect whether you receive a living donor and employment status. The differences in employment rates may also be explained by the fact that employment status determines the choice of dialysis modality and that employed patients with a higher level of education may have an increased interest and access to transplantation compared to unemployed patients [39, 40]. 
In general, employment constitutes a large and important part of our well-being and quality of life, and persons with high depression scores have lower well-being and quality of life and lower employment rates $[4,55,58]$. Studies have also shown that depression scores decreased in patients who were employed posttransplant $[4,44]$. Therefore, less depression may be related to employment and not having a transplantation per se.

The employment rate for kidney failure patients differs between studies and countries, but in general, it is lower than the employment rate in the general population [8]. The variation between countries and continents may be related to differences in the mentioned predictors. Other factors may also have caused some of the differences, such as whether you have private or public health insurance. Kutner et al. in the U.S. showed that patients remaining employed after the initiation of dialysis were twice as likely to have employerpaid group insurance as those who did not remain employed [27]. Likewise, an Italian study by Sangalli et al. showed that employed individuals more often had private health insurance than unemployed individuals [58]. In contrast, a Chinese investigation found no effect on the employment level of having medical insurance [22]. Other studies have shown that the probability of returning to work is reduced if you already have a disability pension [49], but receiving a disability pension may also be explained by being more handicapped and potentially being unable to work. In countries without disability pensions, patients may either be forced to work, or they are dependent on support from their relatives.

This study has identified potential factors that may increase employment rates during dialysis and pre- and posttransplant, including maintenance of pretransplant employment. Educational support, support in maintaining a job during dialysis, and early return to work after transplantation seem important for posttransplant employment.

\section{Comparison with existing reviews}

Only one earlier review investigated the employment rate posttransplant in all adult patients [7]. However, this review included only 9 studies and a population of only 23,059 . They found an employment rate of $39.4 \%$ (weighted mean) posttransplant, while our review included 137,742 individuals with an employment rate of $38.2 \%$ (weighted mean, all studies) and 34.4\% (weighted mean, only studies of patients below 65 years of age). The small differences in employment rates between the two reviews may be explained by the number of included studies and the large variation in employment rates between the individual studies.
A review of 16- to 30-year-old kidney failure patients showed that those on dialysis were more likely to be unemployed than patients having a kidney transplant, corresponding to the findings in our review [74]. Overall, the previous studies support the findings in the present study that dialysis and posttransplant patients have a lower employment rate than the general population.

\section{Strengths and limitations}

The strengths of this review and meta-analysis are the wide search criteria ensuring inclusion of relevant studies and summarizing the knowledge of employment rate for kidney failure patients during dialysis and pre- and posttransplant. However, there are some limitations. First, nearly all studies had no control group and had no comparisons of employment rates with a background population. Second, most of the studies were cross-sectional in design, which limits the evidence of causality between employment and dialysis or kidney transplantation. Third, only a few studies had independent results of the employment rate, and many employment rates were selfreported, introducing a high risk of recall bias. Furthermore, $70 \%$ of the studies on dialysis and $45 \%$ of studies on kidney transplantation included subjects older than 65 years, which may have led to an underestimation of the real employment rate. However, excluding studies with patients $>65$ years of age did not change the employment rate very much. Finally, many studies did not include all the relevant risk factors for unemployment. Moreover, each country has its own social laws and social and health insurance systems to support kidney failure patients staying at work or returning to work, which may have also influenced the employment rate, making it difficult to compare results across countries.

\section{Implications for future research and management of return to work}

This review identified areas of concern among adults with kidney failure. However, caution is necessary regarding the limitations mentioned. As is the case for other diseases and health in general, kidney failure patients are also subject to social inequality regarding employment opportunities. There is a need for larger prospective cohort studies of kidney failure patients that ideally should include more detailed information about social and educational circumstances before and during replacement therapy and include comparisons of similar data with a relevant general background population from the same country.

Future studies should focus more on the predictors for staying employed to better understand the barriers and facilitation possibilities to support people with 
kidney failure to remain employed, including clarification of the importance of dialysis duration, time since diagnosis of severe chronic kidney disease, importance of family resources and specific social measures taken in each country. Future research should also focus on intervention through education, social support systems, and workplace and work task adaptation to find the best support systems to help kidney failure patients stay at work during dialysis and after transplantation. Additionally, studies should focus only on patients of working age with data on employment from independent sources such as tax or social benefits registries.

\section{Conclusion}

Kidney failure patients have a low employment rate during dialysis and pre- and posttransplant. Predialysis employment, a higher education, not having diabetes or depression, being younger, male, or white, receiving a living donor kidney, and a short waiting time before transplantation were all predictors for posttransplant employment. It is important to support kidney failure patients through a combination of clinical and social measures to ensure that they remain in work.

\section{Abbreviations}

PD: Peritoneal dialysis; HD: Haemodialysis; APD: Automated peritoneal dialysis; CAPD: Continuous ambulatory peritoneal dialysis; NHHD: Nocturnal home; Yr: Year; NOS: Newcastle Ottawa Quality Assessment Scale; SD: Standard deviation; n.a.: Not analysed; n.r.: Not relevant.

\section{Supplementary Information}

The online version contains supplementary material available at https://doi. org/10.1186/s12882-021-02552-2.

Additional file 1: Table 7.a. NEWCASTLE - OTTAWA QUALITY ASSESSMENT SCALE, NOS-score for Cross Sectional Studies. Dialysis ${ }^{\S}$. Table 7.b. NEWCASTLE - OTTAWA QUALITY ASSESSMENT SCALE, NOS-SCOre for Cohort Studies. Dialysis ${ }^{\S}$. Table 7.c. NEWCASTLE - OTTAWA QUALITY ASSESSMENT SCALE, NOS-score for Cross Sectional studies. Pre- and Post-transplant ${ }^{\S}$. Table 7.d. NEWCASTLE - OTTAWA QUALITY ASSESSMENT SCALE (NOS-score) for Cohort Studies. Pre- and Post-transplant ${ }^{\S}$. Figure 2. a. Forest Plot of Comparison: Predictors for employment during dialysis. Outcome: Non-diabetic or Diabetic. b. Forest Plot of Comparison: Predictors for employment during dialysis. Outcome: Educational level more than high school or high school or less. c. Forest Plot of Comparison: Predictors for employment during dialysis. Outcome: Dialysis type: HD or PD. d. Forest Plot of Comparison: Predictors for employment during dialysis. Outcome: Gender: Male or Female. Figure 3. a. Forest Plot of Comparison: Predictors for post-transplant employment. Outcome: Gender: Male or Female. b. Forest Plot of Comparison: Predictors for post-transplant employment. Outcome: Educational Level; More Than High School or High School or Less. c. Forest Plot of Comparison: Predictors for post-transplant employment. Outcome: Living donor kidney or deceased donor. d. Forest Plot of Comparison: Predictors for post-transplant employment.

\section{Acknowledgements}

None.

\section{Authors' contributions}

LK performed the systematic research, including reading articles, performed the blinded quality assessment and the meta-analysis, and drafted and revised the article. RC performed the blinded quality assessment and the discussion afterwards of articles to be included in the research and the scores, and drafted and revised the article. TL drafted and revised the article. NHB drafted and revised the article. All authors provided the intellectual content and critical discussion on the assessment and conclusions and provided final approval of the version to be published.

\section{Funding}

The study was supported by the Augustinus Foundation (journal number 19-2321).

\section{Availability of data and materials}

The datasets used and/or analysed during the current study are available from the corresponding author upon reasonable request.

\section{Declarations}

\section{Ethics approval and consent to participate}

Not applicable as this is a systematic review. All the studies that are included have obtained ethical approval and consent as appreciated by the journal in which they have been published.

\section{Consent for publication}

Not applicable.

\section{Competing interests}

None.

\section{Author details}

${ }^{1}$ Centre of Social Medicine, University Hospital Bispebjerg-Frederiksberg, Nordre Fasanvej 57, Vej 8, Opgang 2.2., 2000 Frederiksberg, Denmark. ${ }^{2}$ Department of Transplantation Medicine, Oslo University Hospital, Sognsvannsveien 20, OUS, Rikshospitalet, 0372 Oslo, Norway. ${ }^{3}$ Department of Public Health, University of Copenhagen, Copenhagen, Denmark. ${ }^{4}$ Department of Renal Medicine, Aarhus University Hospital, Palle Juul-Jensnes Boulevard 35, indgang C, plan 2, 8200 Aarhus, Denmark.

Received: 14 January 2021 Accepted: 6 October 2021

Published online: 22 October 2021

\section{References}

1. Couser WG, Remuzzi G, Mendis S, Tonelli M. The contribution of chronic kidney disease to the global burden of major noncommunicable diseases. Kidney Int. 2011;80:1258-70.

2. Levey AS, Eckardt KU, Dorman NM, Christiansen SL, Hoorn EJ, Ingelfinger $J R$, et al. Nomenclature for kidney function and disease: report of a Kidney Disease: Improving Global Outcomes (KDIGO) consensus conference. Kidney Int. 2020;97:1117-29.

3. Chisholm-Burns MA, Ericson SR, Spivey CA, Kaplan B. Health-related quality of life and employment among renal transplant recipients. Clin Transpl. 2012;26:411-7.

4. Danuser B, Simcox A, Studer R, Koller M, Wild P. Employment 12 months after kidney transplantation: an in-depth bio-psycho-social analysis of the Swiss Transplant Cohort. PLoS One. 2017;12:1-17.

5. Manns B, McKenzie SQ, Au F, Gignac PM, Geller LI, for the Canadians Seeking Solutions and Innovations to Overcome Chronic Kidney Disease (Can-SOLVE CKD) Network. The financial impact of advanced kidney disease on Canada pension plan and private disability insurance costs. Can J Kidney Health Dis. 2017;4:1-11.

6. Kramer A, Pipias M, Noordzij M, Stel VS, Andrusev AM, Aparicio-Madre MI, et al. The European Renal Association - European Dialysis and Transplant Association (ERA-EDTA) registry annual report 2016: a summary. Clin Kidney J. 2019;12:702-20. 
7. D'Egidio V, Mannocci A, Ciaccio D, Sestili C, Cocchiara RA, Del Cimmuto A, et al. Return to work after kidney transplant: a systematic review. Occup Med. 2019:69:412-8.

8. OECD. Employment rate (indicator). 2020. https://data.oecd.org/emp/ employment-rate.htm. Assessed 11 May.

9. Hannerz H, Pedersen B, Poulsen OM, Humle F, Andersen LL. A nationwide prospective cohort study on return to gainful occupation after stroke in Denmark 1996 - 2006. BMJ Open. 2011;1:1-5.

10. Tumin D, Chou H, Hayes D Jr, Tobias JD, Galantowicz M, McConnell PI. Employment after hearth transplantation among adults with congenital heart disease. Congenit Heart Dis. 2017;12:794-9.

11. Islam T, Dahlui M, Majid HA, Nahar AM, Mohd Taib NA, Su TT, et al. Factors associated with return to work of breast cancer survivors: a systematic review. BMC Public Health. 2014;14:1-13.

12. Eng M, Zhang J, Cambon A, Marvin MR, Gleason J. Employment outcomes following successful renal transplantation. Clin Transpl. 2012;26:242-6.

13. Eppenberger L, Hirt-Minkowski P, Dickenmann M. Back to work? Socioeconomic status after kidney transplantation. Swiss Med Wkly. 2015;145:1-8

14. Helanterá I, Haapio M, Koskinen P, Grönhagen-Riska C, Finne P. Employment of patients receiving maintenance dialysis and after kidney transplant: a cross-sectional study from Finland. Am J Kidney Dis. 2012;59:700-6.

15. Moher D, Liberati A, Tetzlaff J, Altman DG. The PRISMA group preferred reporting items for systematic reviews and meta-analyses: the PRISMA statement. PLoS Med. 2009;6:1-6.

16. Wells GA, Shea B, O'Connell D, Peterson J, Welch V, Losos M, et al. Newcastle-Ottawa Scale (NOS) for assessing the quality if nonrandomized studies in meta-analyses. 2009. http://www.ohri.ca/programs/clinical_epide miology/oxford.asp.

17. Albatineh AN, Ibrahimou B. Factors associated with quality-of-life among Kuwaiti patients on maintenance hemodialysis. Psychol Health Med. 2019;24:1005-13.

18. Al-Jumaih A, Al-Onazi K, Binsalih S, Hejaili F, Al-Sayyari A. A study of quality of life and its determinants among hemodialysis patients using the KDQOL-SF instrument in one center in Saudi Arabia. Arab J Nephrol Transplant. 2011;4:125-9.

19. AlShahrani MA, Alayed A, AlShehri AH, Solaiman O, Awadalla NJ, Alhomrany M. Depression and impaired work productivity. Saudi I Kidney Dis Transpl. 2018;29:1133-7.

20. Ghani Z, Rydell H, Jarl J. The effect of peritoneal dialysis on labor market outcomes compared with institutional hemodialysis. Perit Dial Int. 2019;39:59-65.

21. Gutman RA, Stead W, Robinson RR. Physical activity and employment status of patients on maintenance dialysis. N Engl J Med. 1981;304:309-13.

22. Huang B, Lai B, Xu L, Wang Y, Cao Y, Yan P, et al. Low employment and low willingness of being reemployed in Chinese working-age maintained hemodialysis patients. Ren Fail. 2017;39:607-12.

23. Imanishi Y, Fukuma S, Karaboyas A, Bruce M, Robinson BM, Ronald L, et al. Associations of employment status and educational levels with mortality and hospitalization in the dialysis outcomes and practice patterns study in Japan. PLoS One. 2017:12:1-11.

24. Kasiske BL, London W, Ellison MD. Race and socioeconomic factors influencing early placement on the kidney transplant waiting list. J Am Soc Nephrol. 1998;9:2142-7.

25. Kutner NG, Brogan D, Fielding B. Employment status and ability to work among working-age chronic dialysis patients. Am J Nephrol. 1991;11:334-40.

26. Kutner N, Bowles T, Zhang R, Huang Y, Pastan S. Dialysis facility characteristics and variation in employment rates: a national study. Clin J Am Soc Nephrol. 2008;3:111-6.

27. Kutner NG, Zhang R, Huang Y, Johansen KL. Depressed mood, usual activity level, and continued employment after starting dialysis. Clin J Am Soc Nephrol. 2010;5:2040-5.

28. Kwan BCH, Chow K, Ma TKW, Yu V, Law MC, Leung CB, et al. Automated peritoneal dialysis in Hong Kong: there are two distinct groups of patients. Nephrology. 2013;18:356-64.

29. Li JW, Wong J, Chak WL, Chau KF. Effect of incident nocturnal home hemodialysis versus incident continuous ambulatory peritoneal dialysis on employment rate, clinical, and laboratory outcomes: a 1-year retrospective observation study. Hemodial Int. 2018;22:308-17.

30. Molsted S, Aadahl M, Schou L, Eidemak I. Self-rated health and employment status in chronic haemodialysis patients. Scand J Urol Nep. 2004;38:174-8.

31. Nakayama M, Ishida M, Ogihara M, Hanaoka K, Tamura M, Kanai H, et al. Social functioning and socioeconomic changes after introduction of regular dialysis treatment and impact of dialysis modality: a multi-centre survey of Japanese patients. Nephrology. 2015;20:523-30.

32. Neumann D, Lamprecht J, Robinski M, Mau W, Girndt M. Social relationships and their impact on health-related outcomes in peritoneal versus haemodialysis patients: a prospective cohort study. Nephrol Dial Transplant. 2018;33:1235-44.

33. Takaki J, Yano E. The relationship between coping with stress and employment in patients receiving maintenance hemodialysis. J Occup Health. 2006;48:276-83.

34. Tanaka M, Ishibashi Y, Hamasaki Y, Kamijo Y, Idei M, Kawahara T, et al. Health-related quality of life on combination therapy with peritoneal dialysis and hemodialysis in comparison with hemodialysis and peritoneal dialysis: a cross-sectional study. Perit Dial Int. 2020;40:1-8.

35. Theorell T, Konarski-Svensson JK, Ahlmén J, Perski A. The role of paid work in Swedish chronic dialysis patients-a nation-wide survey : paid work and dialysis. J Int Med. 1991;230:501-8.

36. Walker RC, Howard K, Tong A, Palmer SC, Marshall MR, Morton RL. The economic considerations of patients and caregivers in choice of dialysis modality. Hemodial Int. 2016;20:634-42.

37. Wilk AS, Tang Z, Hoge C, Plantinga LC, Lea JP. Association between patient psychosocial characteristics and receipt of in-center nocturnal hemodialysis among prevalent dialysis patients. Hemodial Int. 2019;23:479-85.

38. Zimmerman D, Albert S, Llewellyn-Thomas H, Hawker GA. The influence of socio-demographic factors, treatment perceptions and attitudes to living donation on willingness to consider living kidney donor among kidney transplant candidates. Nephrol Dial Transplant. 2006:21:2569-76.

39. Curtin RB, Oberley E, Sacksteder P, Friedman A. Differences between employed and nonemployed dialysis patients. Am J Kidney Dis. 1996;27:533-40.

40. van Manen JG, Korevaar J, Dekker FW, Reuselaars MC, Boeschoten EW, Krediet RT, et al. Changes in employment status in end-stage renal disease patients during their first year of dialysis. Perit Dial Int. 2001;21:595-601.

41. Wolcott DL, Nissenson A. Quality of life in chronic dialysis patients: a critical comparison of continous ambulatory peritonela dialysis (CAPD) and hemodialysis. Am J Kidney Dis. 1988;1 1:402-12.

42. Holley JL, Nespor S. An analysis of factors affecting employment of chronic dialysis patients. Am J Kidney Dis. 1994;23:681-5.

43. Ravindran A, Sunny A, Kunnath RP, Divakaran B. Assessment of quality of life among end-stage renal disease patients undergoing maintenance hemodialysis. Indian J Palliat Care. 2020;26:47-53.

44. Bohlke M, Marini S, Gomes RH, Terhorst L, Rocha M, Poli de Figueiredo CE, et al. Predictors of employment after successful kidney transplantation a population-based study. Clin Transplant. 2008:22:405-10.

45. Chen WC, Chen C, Lee PC, Wang WL. Quality of life, symptom distress, and social support among renal transplant recipients in Southern Taiwan: a correlational study. J Nurs Res. 2007;15:319-28.

46. De Baere C, Delva D, Kloeck A, Remans K, Vanrentererghem Y, Verleden G, et al. Return to work and social participation: does type of organ transplantation matter? Transplantation. 2010;89:1009-2015.

47. De Pasquale C, Veroux M, Pistoriob ML, Papottoa A, Basileb G, Patanèb M, et al. Return to work and quality of life: a psychosocial survey after kidney transplant. Transplant Proc. 2019:51:153-6.

48. Jordakieva G, Grabovac I, Steiner M, Winnicki W, Zitta S, Stefanac S, et al. Employment status and associations with workability, quality of life and mental health after kidney transplantation in Austria. Int J Environ Res Public Health. 2020;17:1254-66.

49. Markell MS, DiBenedetto A, Maursky V, Sumrani N, Hong JH, Distant DA, et al. Unemployment in inner-city renal transplant recipients: predictive and sociodemographic factors. Am J Kidney Dis. 1997;29:881-8. 
50. Matas AJ, Lawson W, McHugh L, Gillingham K, Payne WD, Dunn DL, et al. Employment patterns after successful kidney transplantation. Transplantation. 1996;61:729-33.

51. Matas AJ, Payne W, Sutherland DE, Humar A, Gruessner RW, Kandaswamy $R$, et al. 2,500 living donor kidney transplants: a single-center experience. Ann Surg. 2001;234:149-64.

52. Messias AA, Reichelt AJ, dos Santos EF, Galton C, Albuquerque GC, Kramer JSP, et al. Return to work after renal transplantation. A study of the Brazilian public social security system. Transplantation. 2014;98:1199-204.

53. Miyake K, Endo M, Okumi M, Unagami K, Kakuta Y, Furusawa M, et al. Predictors of return to work after kidney transplantation: a 12-month cohort of the Japan Academic Consortium of Kidney Transplantation study. BMJ Open. 2019:9:e031231 1-8

54. Monroe J, Raiz L. Barriers to employment following renal transplantation. Implications for the social work professional. Soc Work Health Care. 2005;40:61-81.

55. Nour N, Heck CS, Ross H. Factors related to participation in paid work after organ transplantation: perceptions of kidney transplant recipients. J Occup Rehabil. 2015;25:38-51.

56. Petersen E, Baird B, Barenbaum LL, Leviatov A, Koford JK, Shihab F, et al. The impact of employment status on recipient and renal allograft survival. Clin Transplant. 2008;22:428-38.

57. Raiz L. The transplant trap. The impact of health policy on employment status following renal transplantation. J Health Soc Policy. 1997:8:67-87.

58. Sangalli V, Dukes J, Doppalapudi SB, Costa G, Neri L. Work ability and labor supply after kidney transplantation. Am J Nephrol. 2014;40:353-61.

59. Slakey DP, Rosner M. Disability following kidney transplantation: the link to medication coverage. Clin Transpl. 2007;21:224-8.

60. Tzvetanov I, D'Arnico G, Walczak D, Jeon H, Garcia-Roca R, Oberholzer J, et al. High rate of unemployment after kidney transplantation: analysis of the united network for organ sharing database. Transplant Proc. 2014;46:1290-4

61. van der Mei SF, Groothoff J, van Sonderen ELP, van den Heuvel WJA, de Jong PE, van Son WJ. Clinical factors influencing participation in society after successful kidney transplantation. Transplantation. 2006;82:80-5.

62. van der Mei SF, van Son WJ, van Sonderen ELP, de Jong PE, Groothoff JW, van den Heuvel WJA. Factors determining social participation in the first year after kidney transplantation: a prospective study. Transplantation. 2007;84:729-37.

63. van der Mei SF, Kuiper D, Groothoff JW, van den Heuvel WJA, van Son WJ, Brouwer S. Long-term health and work outcomes of renal transplantation and patterns of work status during the end-stage renal disease trajectory. J Occup Rehabil. 2011;21:325-34.

64. Whitlock RS, Seals S, Seawright A, Wynn JJ, Anderson C, Earl TM. Socioeconomic factors associated with readmission after deceased donor renal transplantation. Am Surg. 2017;83:755-60.

65. Jarl J, Gerdtham U, Desatnik P, Prütz KG. Effects of kidney transplantation on labor market outcomes in Sweden. Transplantation. 2018;102:1375-581.

66. Julián-Mauro JC, Cuervo J, Rebollo P, Callejo D. Employment status and indirect costs in patients with renal failure: differences between different modalities of renal replacement therapy. Nefrologia. 2013;33:133-41.

67. Panagopoulou A, Hardalias A, Berati S, Fourtounas C. Psychosocial issues and quality of life in patients on renal replacement therapy. Saudi J Kidney Dis Transpl. 2009;20:212-8.

68. Parajuli S, Singh J, Sandal S, Liebman SE, Demme RA. Self-reported employment status and social participation after successful kidney transplantation. Prog Transplant. 2016;26:92-8.

69. Grubman-Nowak M, Jezewska M, Szafran-Dobrowolska J, Silzien AD, Renka M. Occupational activity after renal tranplantation vs quality of life, personality profile, and stress coping styles. Transplant Proc. 2020;20:S0041-1345(20)30180-9:1-7

70. Sandhu GS, Khattak M, Pavlakis M, Woodward R, Hanto DW, Wasilewski MA, et al. Recipient's unemployment restricts access to renal transplantation. Clin Transpl. 2013;27:598-6.

71. Ismail SY, Luchtenburg A, Gestel KV, Zuidema WC, Weimar W, Busschbach $J$ J, et al. Modifiable factors in access to living-donor kidney transplantation among diverse populations. Transplantation. 2013;96:586-90.

72. Bos M. Can disparity in access to living-donor kidneytransplants between ethnic groups be mitigated? Transpl Int. 2019;32:1028-9.

73. Vedadi A, Bansal A, Yung P, Famure O, Mitchell M, Waterman AD, et al. Ethnic background is associated with no live kidney donor identified at the time of first transplant assessment-an opportunity missed? A single-center retrospective cohort study. Transpl Int. 2019;32:1030-43.

74. Hamilton AJ, Clissold RL, Inward CD, Caskey FJ, Ben-Shlomo Y. Sociodemographic, psykological health, and lifestyle outcomes in young adults on renal replacement therapy. Clin J Am Soc Nephrol. 2017;12:1951-60.

\section{Publisher's Note}

Springer Nature remains neutral with regard to jurisdictional claims in published maps and institutional affiliations.
Ready to submit your research? Choose BMC and benefit from:

- fast, convenient online submission

- thorough peer review by experienced researchers in your field

- rapid publication on acceptance

- support for research data, including large and complex data types

- gold Open Access which fosters wider collaboration and increased citations

- maximum visibility for your research: over $100 \mathrm{M}$ website views per year

At BMC, research is always in progress.

Learn more biomedcentral.com/submissions 